\title{
Proposed Framework of Hybrid Photovoltaic Thermal Systems to Ecotourism in Malaysia
}

\author{
Mohammad Taghi Hajibeigy ${ }^{1, *}$, Aravind $\mathrm{CV}^{1}$, and Rashmi Gangasa Walveka ${ }^{1}$ \\ ${ }^{1}$ School of Engineering, Taylor's University, 47500 Subang Jaya, Selangor, Malaysia
}

\begin{abstract}
Ecotourism is widely recognized for its positive impacts to the environment. Ecotourism is defined as nature-based tourist experiences, which visitors travel to regions for the purpose of appreciating their natural beauty, relaxation and being harmonious with Mother Nature. Ecotourism probably had its foundations in the ethics of conservation, which can help maintain what's left of nature and fosters environmental education. Employing the sustainable energy, paying more attention to the natural resources and developing existing natural resources will have a direct impact to healthier sustainable environment for the inhabitant. If not all, most of the ecotourism sites are located in the remote area in which to utilize electrical energy from the normal grid is difficult or very costly. On the irony, utilizing the conventional nonrenewable energy have negative effect and ruins the ecotourism sites. Therefore, utilizing Hybrid Photovoltaic Thermal (PVT) systems is a fit alternative energy source to serve the limited energy demands of ecotourists sites. The amount of the energy production depends on the visitors' capacity of the site. Since the rural area enjoys the cheap and large field, it is easier to plan and assemble the PVT systems to suffice the needed energy. In this research the sustainability of local environment along with the sustainable usage of energy were considered. This paper presents the sustainable energy usage of tourism in Malaysia and aims to address the impact of sustainable and nonsustainable on the rural area of ecotourism. This paper also addresses some of the emission, carbon reduction and climate change issues that the world is expected to meet soon.
\end{abstract}

Keywords: Ecotourism, Sustainable, Environmental Impacts, Hybrid, Sustainable energy 


\section{Abbreviations}

$\begin{array}{ll}\mathrm{CO}_{2} & \text { Carbone dioxide } \\ \text { IUCN } & \text { International Union for Conservation of Nature } \\ \text { PVT } & \text { Photovoltaic Thermal }\end{array}$

\section{Introduction}

Tourism is a potential matter in environmental, social and economic levels of many government agendas. Government sees tourism as a tool of development giving priority to protect the environments and traditions with minimum negative impacts [1]. Malaysia being the major attraction for the tourist destination in this part of the world enjoys a bigger share of tourist in the entire year [2]. Among the tourism, ecotourism is one of the rapid growing movements in the worldwide tourism industry. Ecotourism is a method of unconventional tourism that aims to achieve economic gain locally by development through natural resource protection. The environment has an inherent value which prevails its value as a tourism asset. Ecotourism relays to the quality of the environment which must be carefully safeguarded from the effect of the activity and type of energy utilizations in its vicinity. The International Union for Conservation of Nature (IUCN) defined ecotourism as "environmentally responsible travel and visitation to relatively undisturbed natural areas in order to enjoy and appreciate nature (and any accompany in cultural features-both past and present) that promotes conservation, has low negative visitor impact and provides for beneficially active socioeconomic involvement of local populations"[3]. World Commission on Environment and Development define sustainable as "Development that meets the needs of the present without compromising the ability of future generations to meet their own needs" [4]. The above definition implies that the important aspect of the definition is to appreciate and protect the nature at the same time an instrument for conservation and sustainable development. In order to comply with the above definition and guard the nature, the source of energy usage must be carefully considered and prohibit the usage of any source of energy which produces environmentally hazard gasses such as carbon dioxide $\left(\mathrm{CO}_{2}\right)$, carbon monoxide $(\mathrm{CO})$, nitrogen dioxide $\left(\mathrm{NO}_{2}\right)$ and phosgene $\left(\mathrm{PO}_{4}\right)$.

Renewable energy resource such as sun is an extremely important part of generating energy needed in the natural rural area since Sun is the most abundance, sustainable and exist everywhere without any cost. It aims to assist in the reduction of the emission of greenhouse gases which are produced by non-renewable energy sources such as fossil fuel. However, the newly designed hybrid PVT systems can produce both electrical energy and the same time high thermal energy. Since the heat accumulated on the PV reduces the PV efficiency, the removal of the large amount of thermal energy from the PV not only help to maintain the PV electrical efficiency but also to serve as the useful thermal energy needed in the rural area. The aims of this paper is to investigate environmental impacts of energy source usage in relation to ecotourism and focuses on environmental impact of the energy source usage on ecotourism in Malaysia.

\subsection{Ecotourism in Malaysia}

Malaysia is an exceptional country in terms of its tourist attractions and rich natural resources. The utmost important characteristics of the country are its ethical and cultural diversity, ecotourism attractions, and diverse natural resources. The Belum Temengor Forest Complex is reputed to be more than 130 million years old. This is the oldest in the 
world, and even older than the Amazon forest and Congo basin. Ten top attractions for Malaysian ecotourism which have outstanding natural assets and present opportunities for local people to involve in ecotourism development are shown in Table 1 in rough order of priority [5].

Table 1. Ten Top Attractions for Malaysian Ecotourism and their Natural Assets [5].

\begin{tabular}{cll}
\hline N & Place & Natural assets \\
\hline 1 & Lower Kinabatangan River, Sabah & Proboscis monkeys, river, wildlife \\
2 & Wang Kelian, Perlis & Limestone, caves and forest \\
3 & Kenong Forest Park, Pahang & Elephants, caves, streams \\
4 & Belum / Temenggor, Perak & Wildlife, forest and lake \\
5 & GunungStong, Kelantan & Mountain, waterfall, rockfaces \\
6 & Ulu Muda, Kedah & Forest, lake and sandstone \\
7 & TasikBera, Pahang & Lake, culture, fish \\
8 & Hose Mountains, Sarawak & Forest, trekking, birdwatching \\
9 & TasikKenyirl, Terengganu & Lake, boating, trekking, fishing \\
1 & PulauKuku, Johor & Mangroves, wildlife, seafood \\
0 & & \\
\hline
\end{tabular}

\subsection{Environmental impact of ecotourism}

Ecotourism differs from conventional tourism because it mainly concerns the perceptions and values of individuals which influenced a great portion appreciation of environment. Therefore, it reduced the scale of exploitation of these natural resources [6]. In comparison to other type of tourism, manners, such as the proper management of waste at the sites and recycling are stressed in ecotourism. Ecotourism is specific in nature and it impacts the environment as well as the changes in people's attitudes in a positive sense. Hence, it is distinguished from other tourism forms owing to its natural area surroundings [7]. On the other hand, sustainable ecotourism objective is to address the needs of to sustain the visited environments, help to educate the local communities in regards to their natural surrounding and to preserve the virginity of the nature [8]. However, the impact of the tourism on the destination could be negative. Among the negative impact is the generating Carbon dioxide $\left(\mathrm{CO}_{2}\right)$ which is produced by using non-renewable energy source such as fossil fuel.

\subsection{Carbon dioxide $\left(\mathrm{CO}_{2}\right)$ damage}

Carbon emissions, most particularly $\mathrm{CO}_{2}$, are part of a group of gases that harmfully impact the quality of our air and raise the greenhouse effect. Real world activities such as energy consumption, waste disposal and transportation contribute towards carbon footprint as these activities contribute towards $\mathrm{CO}_{2}$ Ecological Footprint is a common baseline for Carbon Footprint - emission of gases contributing to climate change, associated with human production or consumption activities. In a rural tourism setting, all service providers to tourists may contribute to the deterioration of the environment in the course of their tourism 
activities. When consumption (operational practices and activities of tourists) supersedes carbon offset initiatives, mitigation approaches are needed [9].

\subsection{Carbon Offset Plan}

In order to have an effective offset plan, the true measures are vital to evaluate proper offset methods.

A carbon tax on aviation fuel would particularly affect long-haul flights, because of high emissions, and short-haul flights and the emission during take-off and landing [10].Taxation should be in accordance with the amount of pollution they generate and use the fund to reverse the pollution by implanting trees, promote a healthier environment, promote sustainable energy, and other forms of contribution to the Mother Nature on the location sites. The plan should be able to calculate the carbon emission for all the activities and offer offset price that is tied to a chosen project before the payment method is determined. The mentioned process is shown in the Figure 1.

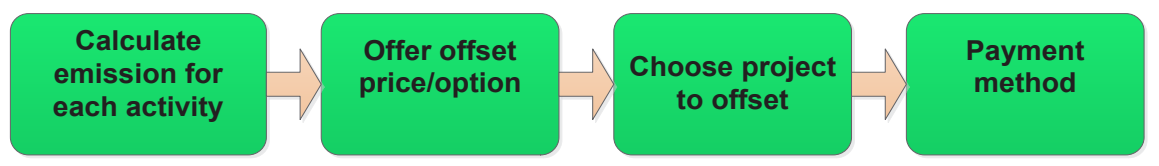

Fig.1. Offset carbon mission plan [9].

It is recommended that the vehicle operates on the site will be battery operated and the energy for using to recharge battery comes from the PVT source. The usage of renewable energy source without proper plan hinder and cause limitation on the growth of the area. The limitation in any aspect prevents growth in any form and manner such as financial impact on the local residence as well as on a national level and impact on the development of natural resources. The fund generated from the tourists can help the local community's living standard, physical, economic and social environments of destinations which solely depend on the quantity and the quality of the ecotourists. There are several ways to minimize the limitations for ecotourism. One approach is to plan for the usage of sustainable energy in place of the pollution sources energy such as fossil fuels that is non-renewable, hazardous and unnatural phenomenon in the earth's atmosphere like Global warming. Most clean, natural and renewable energy comes either directly or indirectly from the Sun. Therefore, the best answer that could be uttered out lies in the Sun. The Sun stands as a reliable renewable source of energy.

\subsection{Energy Demands at the ecotourists Site}

As the number of ecotourists increases the energy demand proportionally will increase as well. The PVT systems can be used to supply the demands and replaces the existing fossil fuel energy. The eco sites normally located in the rural areas and are not comfortable to transfer the energy from the normal conventional source via grid to these areas. Besides, the conventional method is not in line with the concept of ecotourism and in fact is hazardous to the Mother Nature which will ruins the eco-system. The fit alternative method is the solar energy. The solar energy is present everywhere, renewable, the most abundant, free and environmentally friendly [11]. Solar energy can cover a significant percentage of tourism infrastructures. The PVT systems can cover both heat demand and electrical demand. The proposed systems include a PV array, enhanced solar collectors, solar charger for optimized 
energy harvesting, and a converter-inverter module to supply ac and dc electrical energy. The PVT systems deliver both electrical energy to suffice the electrical energy need while the thermal system produces thermal energy which can heat water to be used for shower, pool or to be used in radiator to warm the rooms and offices. The application of PVT systems in the industry is suggested as a reliable solution for a wider use of solar energy systems [12]. Globally the usage of sustainable and renewable energy source has been increased. Figure 2 shows the renewable energy consumption by region in the word.

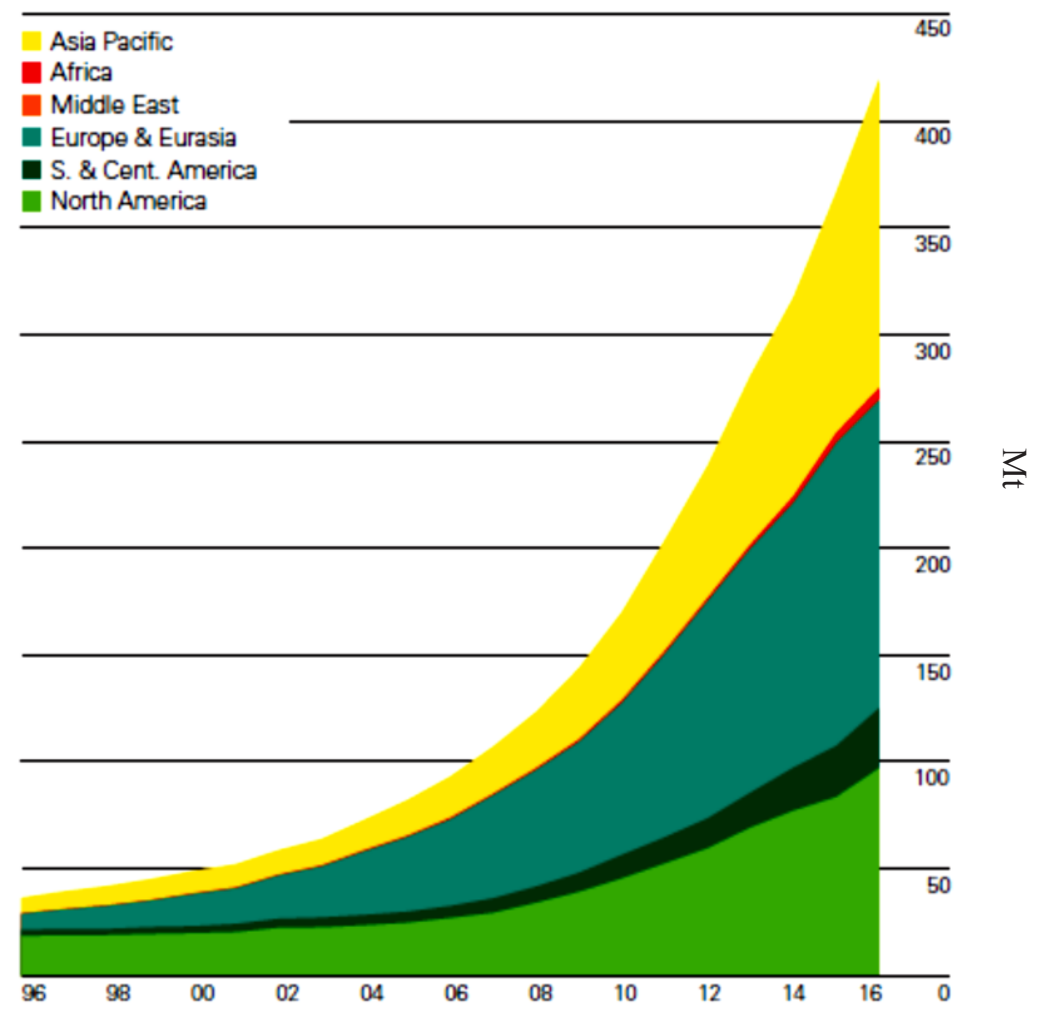

Fig. 2. Renewable energy consumption by region, year 1996 - 2016 vs. Million tonnes oil equivalent (Mtoe) [13].

The graph shows the exponential increase of renewable energy consumption in different continent. This is in favour of the natural area and better sustain the eco system from ecological effect caused by $\mathrm{CO}_{2}$ which is generated by producing energy from non-renewable energy fossil fuel. Implementing PVT systems in rural area will boost the total renewable energy consumption of Malaysia which in turn help the ecological and sustain the ecotourists area. Generating $1 \mathrm{~kW}$ electrical energy by PV system producing $150 \mathrm{kWh}$ each month prevents $75 \mathrm{~kg}$ of fossil fuel from being extracted. It avoids $150 \mathrm{~kg}$ of $\mathrm{CO}_{2}$ from entering the atmosphere and keeps $473 \mathrm{~L}$ of water from being consumed [14]. Figure 3 shows Malaysia energy consumption for the past 26 years. The graph shows a steady increase on the yearly energy consumption of Malaysia. This trend is alarming to the ecological system which put more pressure to use alternative method to non-renewable energy source to protect ecological infrastructure. 


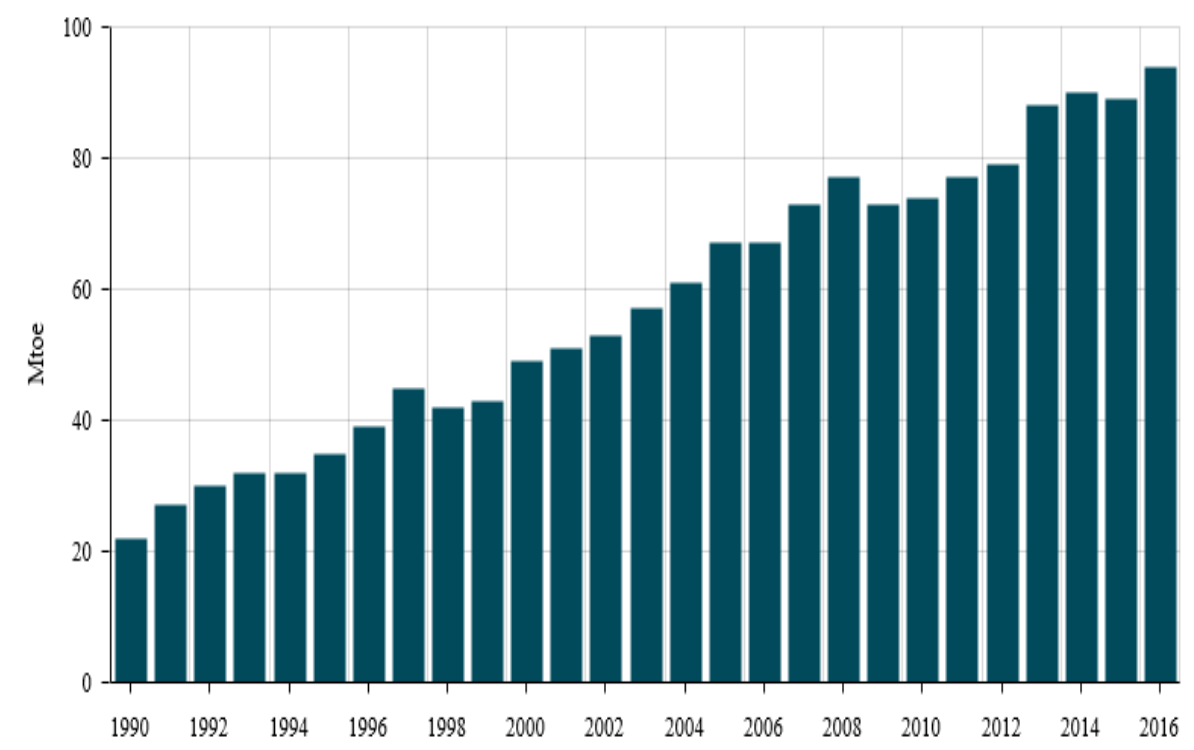

Fig. 3. Malaysian energy consumption, year 1996 - 2016 vs. million tonnes oil equivalent (Mtoe) [13].

\section{Energy Requirement at the Ecotourists Site}

It is highly important and critical to calculate and analyse the energy required for the ecotourism sites. Malaysia being a tropical country average sun insolation ranges about 4.8 $\mathrm{kWh} / \mathrm{m}^{2} /$ day $-5.8 \mathrm{kWh} / \mathrm{m}^{2} /$ day. Photovoltaic (PV) system is well recognized and widely utilized to convert the solar radiation to electric energy. The normal factor influence the energy management is the active energy utilization $(\mathrm{KWh})$, the reactive energy consumption (KVARh) and the peak demand (KW). Conventionally the utility system put their effort on the reduction of KWh consumption and on addressing the required reactive energy to improvise the power factor [15]. Nadarajan and Aravind [2] use the below procedure for the demand analysis and the net KW demand.

Let the contracted power be (PC), the maximum demand be (PD) the power used in excess (PE) computed as:

$$
\begin{gathered}
P E=P C-P D \\
P D=P D m \times K D
\end{gathered}
$$

where $P D m$ is the actual peak demand value from the maximum demand meter and $K D$ is the demand factor.

The penalty by the supplier to the utility is computed as:

$$
P P=(P C-P D) x K P
$$

where $K P$ is the penalty factor. Therefore the actual $\mathrm{KW}$ value $(P A)$ computed is given by

$$
P A=[(P C-P D) \times K P]+[P D m \times K D]
$$




\subsection{Energy production by utilizing PV}

The generation of electrical energy solely relies on the solar radiation, the total surface area of the PV being utilized and the efficiency of the PV itself. Figure 4 shows annual average solar radiation energy for different city in Malaysia.

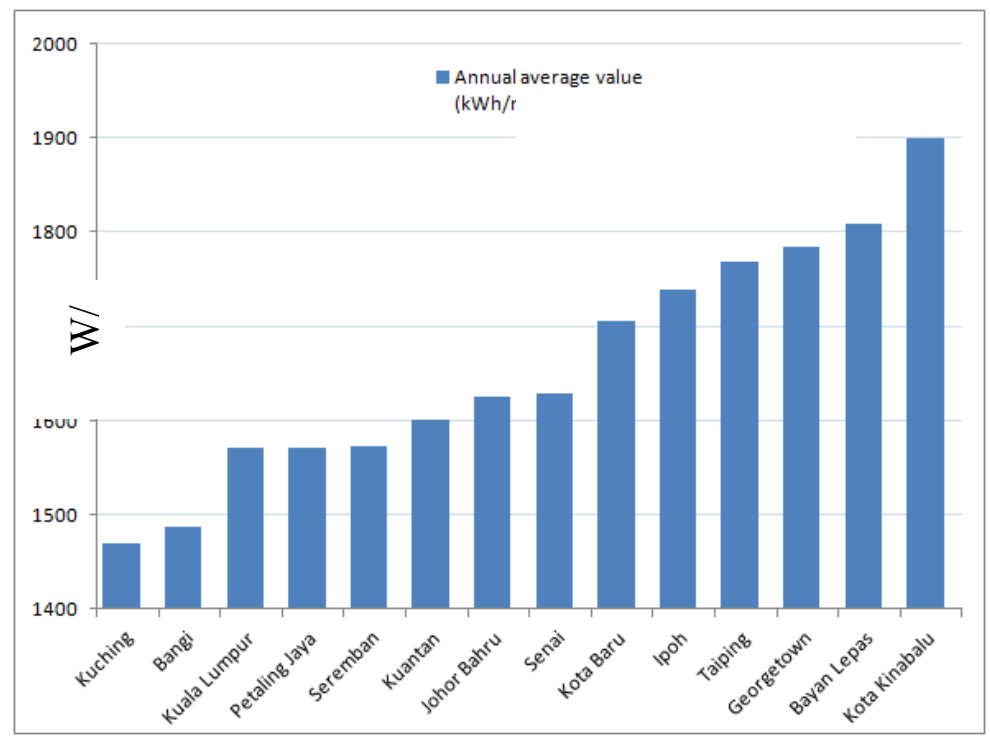

Fig. 4. Aannual average sun radiation energy watt $\left(\mathrm{W} / \mathrm{m}^{2}\right)$ for different city in Malaysia [16].

Figure 4 above shows that for every square meter $\left(1 \mathrm{~m}^{2}\right)$ of PV produces $1900 \mathrm{~W}$ of energy per hour in Kota Kinabalu, compared to only $1571 \mathrm{~W} / \mathrm{h}$ in Kuala Lumpur; assuming 100\% solar cell efficiency. The electrical energy (Watt) obtained can be calculate from equation (5).

$$
K W h=H \times G \times \eta \times S
$$

Where $\mathrm{H}$ is the total hours of sun light, $\mathrm{G}$ is the sun radiation $\left(\mathrm{W} / \mathrm{m}^{2}\right), \eta$ is the efficiency of PV module and $\mathrm{S}$ is the total surface area of the PV. Using equation (5) a solar panel with efficiency of $15 \%$ only produces $285 \mathrm{Wh}$ in Kota Kinabalu and $235 \mathrm{Wh}$ in Kuala Lumpur. With 5 hours of total solar radiation per day, and with an installation of $10 \mathrm{~m}^{2}$ of solar PV can produce $1.425 \mathrm{kWh}$ in Kota Kinabalu, and $1.178 \mathrm{kWh}$ in Kuala Lumpur daily [16]. Table 2 shows the estimated total electrical power generation by different PV surface area coverage with the efficiency of $15 \%$ for a full day assuming 5 hours of full solar radiation without cloud. The table was generated based on the equation (5) and the yearly average solar radiation on each location. 
Table 2. Electrical Energy generated by the PV for one day for different PV surface area in different locations in Malaysia.

\begin{tabular}{|c|c|c|c|c|c|c|}
\hline Location & $(10$ & $(50$ & $(200$ & $(500$ & $(1000$ & $(5000$ \\
\hline $\mathrm{s} \quad$ in & $\left.\mathrm{m}^{2}\right)$ & $\left.\mathrm{m}^{2}\right)$ & $\left.\mathrm{m}^{2}\right)$ & $\left.\mathrm{m}^{2}\right)$ & $\left.\mathrm{m}^{2}\right)$ & $\left.\mathrm{m}^{2}\right)$ \\
\hline \multirow[t]{2}{*}{ Malaysia } & KWh/ & KWh/ & $\mathrm{KWh} /$ & $\mathrm{KWh} /$ & $\mathrm{KWh} /$ & $\mathrm{KWh} /$ \\
\hline & Day & Day & Day & Day & Day & Day \\
\hline Kota & \multirow{2}{*}{14.25} & \multirow{2}{*}{71.25} & \multirow{2}{*}{285.00} & \multirow{2}{*}{712.50} & 1425.0 & 7125.0 \\
\hline Kinabalu & & & & & 0 & 0 \\
\hline Bayan & \multirow{2}{*}{13.58} & \multirow{2}{*}{67.88} & \multirow{2}{*}{271.50} & \multirow{2}{*}{678.75} & 1357.5 & 6787.5 \\
\hline Lepass & & & & & 0 & 0 \\
\hline Georget & \multirow{2}{*}{13.35} & \multirow{2}{*}{66.75} & \multirow{2}{*}{267.00} & \multirow{2}{*}{667.50} & 1335.0 & 6675.0 \\
\hline own & & & & & 0 & 0 \\
\hline \multirow{2}{*}{ Ipoh } & \multirow{2}{*}{13.05} & \multirow{2}{*}{65.25} & \multirow{2}{*}{261.00} & \multirow{2}{*}{652.50} & 1305.0 & 6525.0 \\
\hline & & & & & 0 & 0 \\
\hline Kota & \multirow{2}{*}{12.83} & \multirow{2}{*}{64.13} & \multirow{2}{*}{256.50} & \multirow{2}{*}{641.25} & 1282.5 & 6412.5 \\
\hline Baru & & & & & 0 & 0 \\
\hline Johor & \multirow{2}{*}{12.23} & \multirow{2}{*}{61.13} & \multirow{2}{*}{244.50} & \multirow{2}{*}{611.25} & 1222.5 & 6112.5 \\
\hline Baru & & & & & 0 & 0 \\
\hline \multirow{2}{*}{ Kuantan } & \multirow{2}{*}{12.00} & \multirow{2}{*}{60.00} & \multirow{2}{*}{240.00} & \multirow{2}{*}{600.00} & 1200.0 & 6000.0 \\
\hline & & & & & 0 & 0 \\
\hline \multirow[t]{2}{*}{ Seremba } & \multirow{2}{*}{11.78} & \multirow{2}{*}{58.88} & 23550 & 58875 & 1177.5 & 5887.5 \\
\hline & & & 250.50 & 500.13 & 0 & 0 \\
\hline Bangi & 11.10 & 55.50 & 22200 & 55500 & 1110.0 & 5550.0 \\
\hline & & & & & 0 & 0 \\
\hline Kuching & 10.95 & 54.75 & 219.00 & 547.50 & 1095.0 & 5475.0 \\
\hline & & & & & 0 & 0 \\
\hline
\end{tabular}

The electrical and thermal efficiencies of the PVT systems are independent of location. However, the solar radiation and also, to a lesser extent, ambient conditions such as temperature and wind speed will strongly influence the total energy generation. The electrical and thus thermal efficiencies are considered to vary in the ranges $18.0-15.3 \%$ and $60-50 \%$, respectively, for operating temperatures between $25 \mathrm{C}^{\circ}$ and $85 \mathrm{C}^{\circ}$ [17]. With the thermal efficiency given above the total energy of the PVT systems can be higher than given calculated value. For a PV module in air, the total convective energy $\left(\mathrm{q}_{\text {conv }}\right)$ exchange from a module surface is shown in Equation (6).

$$
q_{\text {conv }}=h_{c} \cdot A \cdot\left(T_{\text {module }}-T_{\text {ambient }}\right)
$$

where hc is the convective heat transfer coefficient, A is the surface area of the PV module, $\mathrm{T}_{\text {module }}$ is the temperature of the module and $\mathrm{T}_{\text {ambient }}$ is the ambient temperature surrounding the systems [18].

\section{Modelling Framework and Methodology}

\subsection{PVT Hybrid Systems Design}

PVT hybrid systems consisted of two main parts, electrical system and thermal system. The PV module conventionally produces electrical energy while the thermal unit produces thermal energy. The electrical system consisted of PV module, charge controller, battery, convertor and invertor for ac and dc voltage usage. The thermal system consisted of aluminium plate, 
heatsinks, thermal container, thermal transfer fluid, heat exchanger, thermal storage tank and pump. The control unit regulate the speed and operation of pump based on the temperature difference of thermal fluid in the thermal container and the water in the thermal storage tank. The proposed entire structure of the hybrid PVT systems is shown in Figure 5.

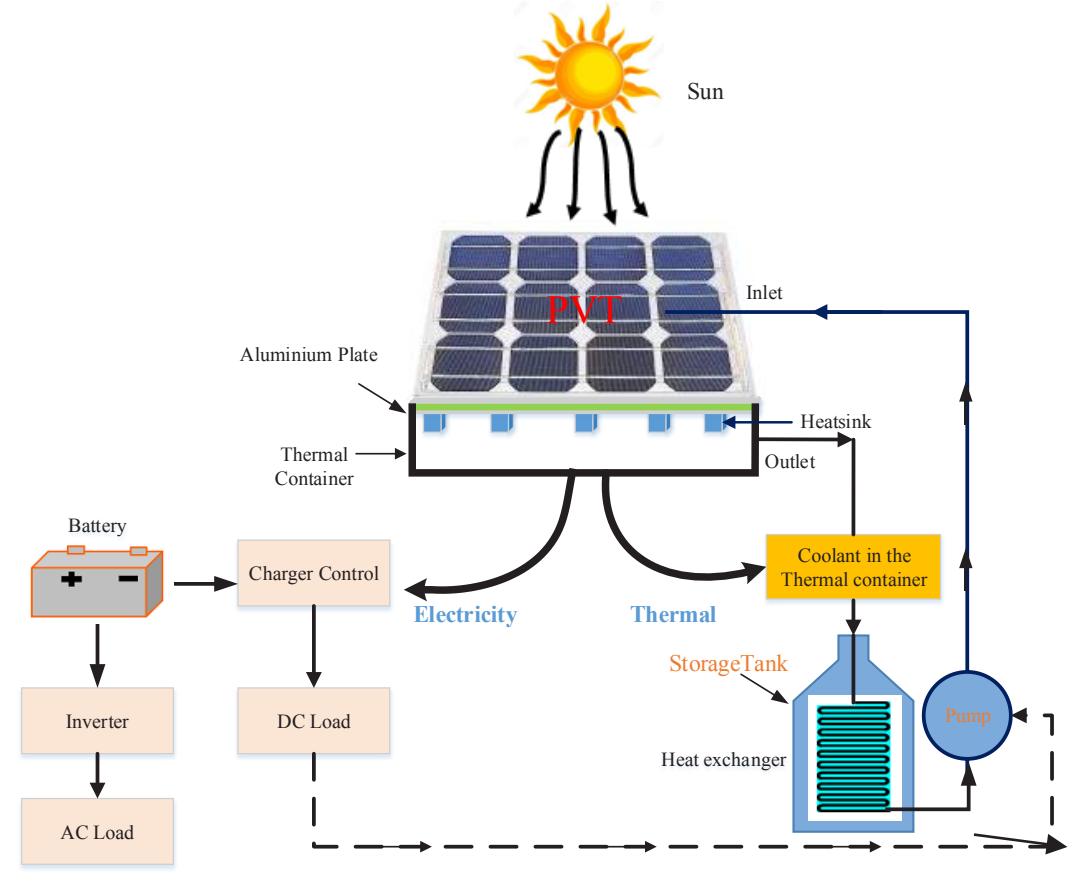

Fig. 5. Photovoltaic Thermal Hybrid PVT Systems.

\subsection{Systems Configurations}

The designed hybrid PVT systems consisted PV module, aluminum plate, heatsinks and thermal container. The aluminum plate is directly attached below the PV module via thermal glue to absorb the thermal energy from the PV module. The heatsinks are welded on the bottom layer of the aluminum plate to further remove the heat from the aluminum plate. The thermal container is made of acrylic which holds coolant. The coolant used as the transfer medium. The assembled unit is placed inside a thermal container, which the unit sat on the top of the thermal container. The heatsinks also fit inside the container which is immersed in the coolant. Each layer of the Hybrid PVT systems is shown in Figure 6. 


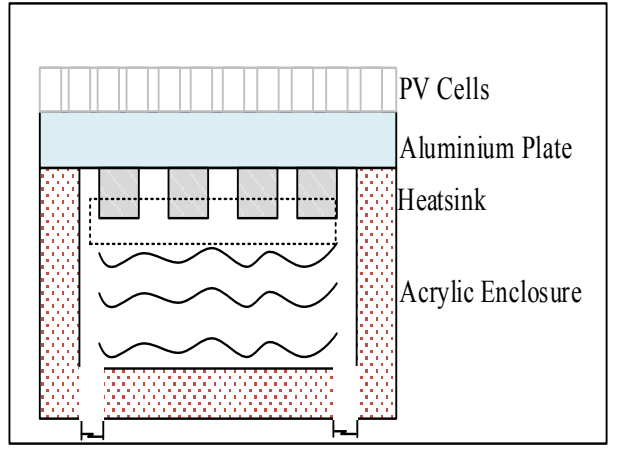

(a) Phase layered system setup

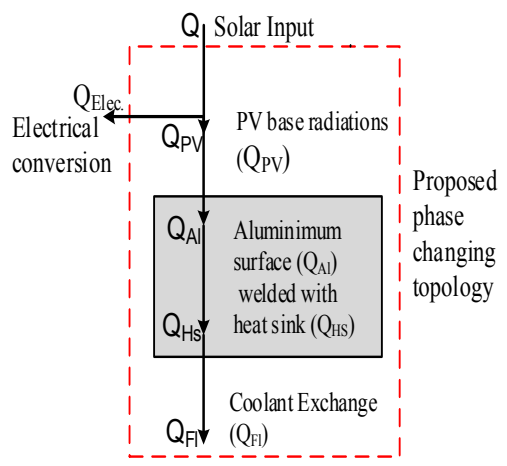

(b) Stage changing topology

Fig. 6. Hybrid PVT Systems with thermal container [19].

\section{Conclusions}

It is evident that ecotourism has positive impacts on the environment and economy of the local and the country as whole. The development of ecotourism can support both in preservation and conservation and of the environment at the destination while the negative effect cannot be ignored. The negative effect of ecotourism mostly comes from creating $\mathrm{CO}_{2}$ by using fossil fuel energy source. However, there are advanced technologies and designs available for hybrid PVT systems to meet the specific demands and characteristics of the tourism facilities. In order to develop the harness and the abundant amount of solar energy radiation by PVT, the systems with the hybrid controller is suggested. In order to effectively examine the sustainable development of the tourism destination in Malaysia a system to assess sustainability from the integrated perspective need to be in placed in order to evaluate the existing effect of the energy source usage.

\section{Acknowledgement}

This research was supported by Taylor's SoE Research Budget scheme towards the measurement and testing equipment.

\section{References}

1. A. Liu and G. Wall, "Planning tourism employment: a developing country perspective," Tourism Management, vol. 27, pp. 159-170, (2006)

2. C.V. Aravind, M. AL-Atabi, J. Ravishankar, A. Malik, and E. T. Ambikarajah, "Eco-Tourism Sustainability Through PV Technology: A Comprehensive Review," Journal of Engineering Science and Technology, vol. 8, pp. 654-669, (2013)

3. C. Lascurain. (1996) World Conservation Union. Available: http://www.iucnworldconservationcongress.org

4. NGO and C. o. Education, "Our Common Future," U. Nations, Ed., ed. U.S.A.: WCED, (1987)

5. I. Louis, G. Davison, J. Payne, W. Yap, P. Fletcher, and E. Lina, "Malaysian National Ecotourism Plan," vol. Excecutive Summary, M. o. Culture, Ed., ed. Malaysia, pp. 41-48, (1996) 
6. I. Thomas, "Defining Tourism," USA:Rosen Publishing Group Inc, (2004)

7. D. N. Ravens, The Natural and Human Environment Combined. New York: Children's Press, (1996)

8. M. Briffa, \& Le,G. Conventional Links to Sustainable Development Nerd Press, (2004)

9. V. Nair, "Conceptualising Carbon Footprint and Offset Measures for Rural Tourism Destinations: A Possible Plan for Himalaya? ," Leh, Ladakh June (2014)

10. R. S. J. Tol, "The impact of a carbon tax on international tourism," Transport and Environment, vol. 12, pp. 129-142, (2007)

11. B. K. Maskey, "Development Governance. Agenda for Action. Centre for Development and Governance,", ed. Kathmandu, (2000)

12. G. Peterson and L. D., "People and their behavior: A challenge for recreation management," Journal of Forestry, vol. 77, pp. 343-346, (1979)

13. (4 November 2017). Global Energy Statisctical Yearbook. Available: https://yearbook.enerdata.net/total-energy/world-consumption-statistics.html

14. Leung, D. Y. C, Yang, and Y., "Wind energy development and its environmental impact: A review," Renewable and sustainable energy review, vol. 16, pp. 1031$1039,(2012)$

15. Nadarajan and C.V. Aravind, "Peak Demand Analysis for the Look-ahead Energy Management System," presented at the eureca, Taylor's University, (2013)

16. (2017, 5 November) Sustainable Energy and Environment Forum. Available: http://www.thegreenmechanics.com/2013/08/annual-solar-radiations-indifferent.html

17. A. Ramos, M. A. Chatzopoulou, I. Guarracino, J. Freeman, and C. N. Markides, "Hybrid photovoltaic-thermal solar systems for combined heating, cooling and power provision in the urban environment," Energy Conversion and Management, vol. 150, pp. 838-850, 15 October (2017)

18. A.D. Jones and C.P. Underwood, "Thermal Model For Photovoltaic Systems," Solar Energy, vol. 70, pp. 349-359, (2001)

19. M. T. Hajibeigy, C.V. Aravind, M. Al-Atabi, and P. Hoole, "Heat Response Model for Phase Layered Topology in a Photovoltaic Thermal System,"Indonesian Journalof Electrical Engineering and Computer Science, vol. 7, pp. 52-60, July (2017) 